\title{
BIDIRECTIONAL CHOPPER FED ELECTRIC DRIVE
}

\author{
Rajdip Singh $^{1}$, Raju Yanamshetti ${ }^{2}$, Premakumar Waggi ${ }^{3}$ \\ ${ }^{1}$ M.Tech in Power Electronic P.D.A.C.E, Gulbarga, Karnataka \\ ${ }^{2}$ Prof E \& CE Dept. P.D.A.C.E, Gulbarga, Karnataka \\ ${ }^{3}$ M.Tech in VLSI Design V.T.U.R.C, Gulbarga, Karnataka
}

\begin{abstract}
Battery fed electric drives is mainly used for electric vehicle application in which battery is main source of energy. The combination of battery and ultra capacitor forms efficient Energy Storage System (ESS) for traction application. Bidirectional $D C-D C$ converter is used to interface two energy storage and to control power flow. The system drives a dc motor. Matlab simulation with experimental results are presented to verify the validity of the system
\end{abstract}

Keywords: - fossil fuels, Energy Storage System (ESS), ultra capacitor,

\section{INTRODUCTION}

Fuel resources across the world is depleting at a high rate. There is large dependency of the transportation sector on petroleum as the primary fuel and also there is a vast greenhouse gas emission that is degrading the quality of air and causing harm to life and environment. Due to these reasons there is growing demand for electric vehicles. Battery fed electric drives is mainly used for electric vehicle application in which battery is main source of energy [1]. The efficiency of the electric drive can be increased by increasing the voltage. Bidirectional DC to DC converters boost up the voltage level of the electrical storage system to the higher voltage level and thereby reducing the current level and hence the losses. Also Bidirectional DC to DC converter facilitates the reverse power flow back into the ESS during regenerative braking operation and hence further increasing the efficiency. These features of the Bidirectional DC to DC converter makes it a better option for power conversion in the EV drive, thereby reducing overall cost, size and weight of the system along with increasing efficiency and achieving regenerative braking energy . Battery is subjected to time varying current demands including acceleration and regenerative braking. In battery-based energy storage systems, power density of the battery needs to be high enough to meet the peak power demand. Although batteries with higher power densities are available, they are typically priced much higher than the lower power density batteries. A typical solution to this problem is to increase the size of the battery but this also causes an increase in cost. Compared to batteries, ultra-capacitors have a high power density, but a lower energy density. This combination offers better performance in comparison to the use of either of them alone. [1]The lithium-ion battery has been proven to have excellent performance in portable electronics and medical devices. The lithium-ion battery has high energy density, has good high temperature performance, and is recyclable. The promising aspects of the Li-ion batteries include high specific power and high specific energy of and long battery life. These excellent characteristics give the lithium-ion battery a high possibility of replacing $\mathrm{Ni} \mathrm{MH}$ as next-generation batteries for vehicles. [2]. Fast and sudden battery discharge during acceleration, or fast charging during regenerative braking can be avoided with the help of ultra capacitors. Besides, ultra capacitors allow regenerative braking even with the batteries fully charged. [4]. Pulse width modulation technique is used for controlling the speed of the motor. [5]

In this paper a system is proposed which drives the dc motor fed by bidirectional chopper. A combination of battery and ultracapacitor forms a energy storage system and the pwm signals required for switching of converter is generated by using Atmega16L microcontroller. The system drives the DC motor and it is suitable for vehicle traction application

\section{SYSTEM OVERVIEW AND BLOCKDIAGRAM}

The motor to be controlled is fed by a DC source that is battery. The battery voltage need to boost up before feeding to the motor in order to meet the load requirement therefore the system consist of boost converter. By varying duty cycle, output can be varied. The boost converter consists of two switches which are alternatively triggered by the pwm signal. The pwm signals are generated by the microcontroller. It has special feature that is by controlling the special registers (OCR: Output compare register and TCR: Timer control register), the duty cycles can be controlled .The motor runs at particular constant speed determined by the microcontroller and when load increases it draws more current which reduces terminal voltage. This output voltage is sensed and compared with the reference voltage which generates difference or error signal. This error signal is given to pwm generator Ic SG3524 which adjusts the duty cycle until a desired level of speed is achieved. The output of pwm generator is isolated from power circuit using photocoupler PC817. Thus a closed loop control is achieved which drives the motor at constant speed preset by the microcontroller irrespective of load variations. The block diagram is as shown in figure. 1 


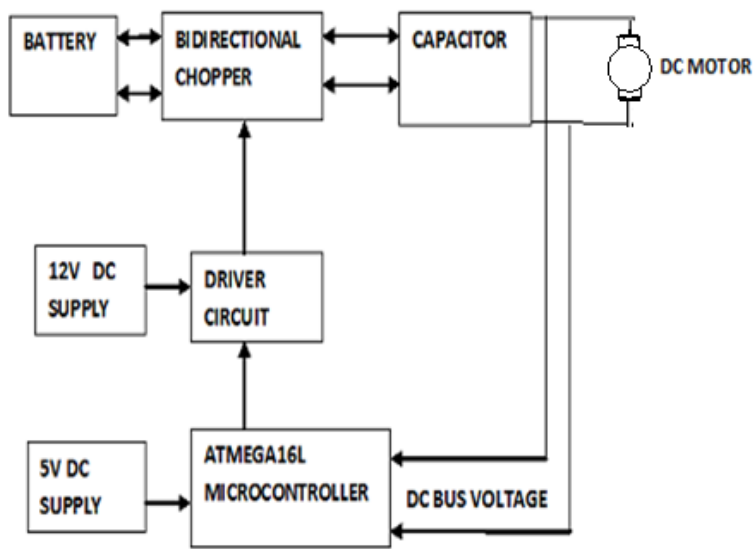

Fig1. Block diagram

\section{CIRCUIT DESCRIPTION}

During motoring operation power flow from battery to motor. When switch T2 is turned on, the current flows through battery, inductor and switch T2. As shown by loop I1 in figure 2

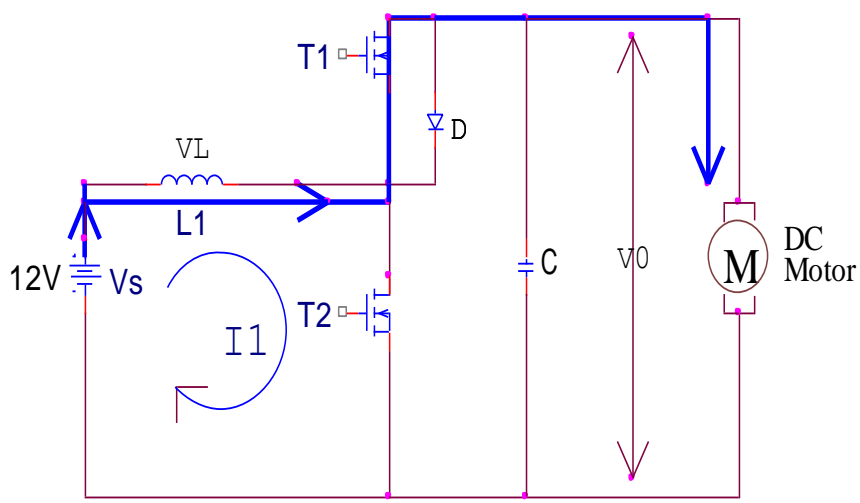

Fig 2.Boost operation

Battery supply energy to the inductor and a voltage develops across it. When switch T2 is turned off and T1 turned on, motor receives energy from both inductor as well as battery as shown by solid line in figure 2 . Now current flows through switch T1.

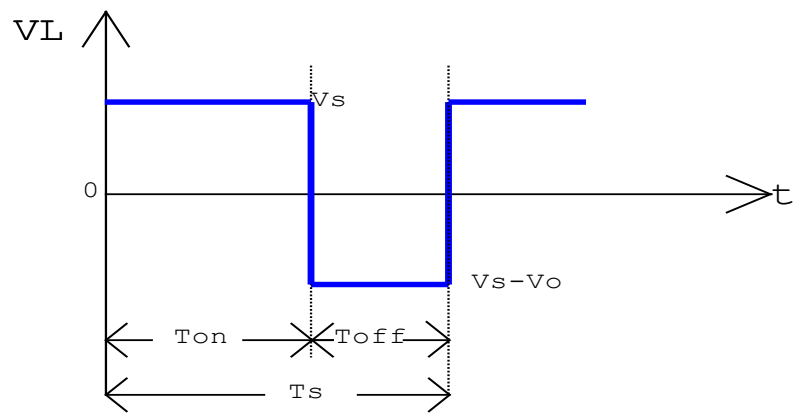

Fig 2.Voltage across inductor over one time period

In steady state the time integral of inductor voltage Over one time period must be zero that is

$$
\mathrm{V}_{\mathrm{s}} \mathrm{T}_{\text {on }}+\left(\mathrm{V}_{\mathrm{s}}-\mathrm{V}_{0}\right) \mathrm{T}_{\text {of }}=0
$$

Dividing both side by $\mathrm{T}_{\mathrm{s}}$ and rearranging terms yield

$$
\begin{aligned}
& \mathrm{Vs}\left(\mathrm{T}_{\mathrm{on}}+\mathrm{T}_{\mathrm{off}}\right)-\mathrm{V} \mathrm{T}_{\mathrm{off}}=0 \\
& \mathrm{~V}_{0} \mathrm{~T}_{\text {off }}=\mathrm{V}_{\mathrm{s}} \mathrm{T}_{\mathrm{s}} \\
& \mathrm{V}_{0}=\mathrm{V}_{\mathrm{s}} \mathrm{T}_{\mathrm{s}} / \mathrm{T}_{\text {off }}
\end{aligned}
$$

The average output voltage is given by

$$
\mathrm{V}_{0}=\mathrm{V}_{\mathrm{s}} /(1-\mathrm{D})
$$

By varying the duty cycle $\mathrm{D}$ the average output voltage $\left(\mathrm{V}_{0}\right)$ can be varied which varies the speed of motor. Practically switch is turned on and off so that duty cycle is variable and the required output voltage is more than the source voltage.

\subsection{Modes of Operation}

Depending on the value of duty cycle electric vehicle operation can be classified into different modes operation.

\subsubsection{Mode1: Constant Speed Operation}

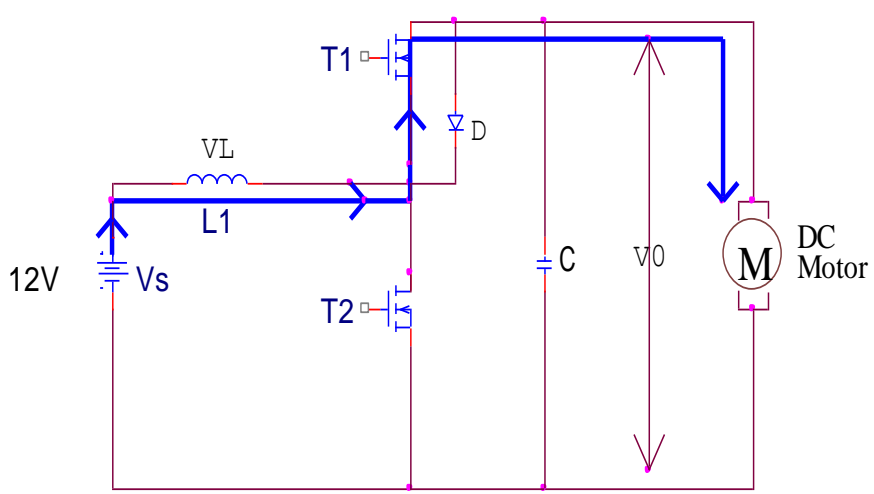

Fig 3.Constant speed operation

As long as duty cycle is constant the average output voltage is constant and the motor drives at constant speed. when duty cycle is fixed, near to unity the motor is driving at high constant speed. When duty cycle D is smaller and fixed near to zero, the motor is driving at low constant speed. During this mode battery alone supplies energy to motor as shown in figure 3

\subsubsection{Mode2: Acceleration Operation}

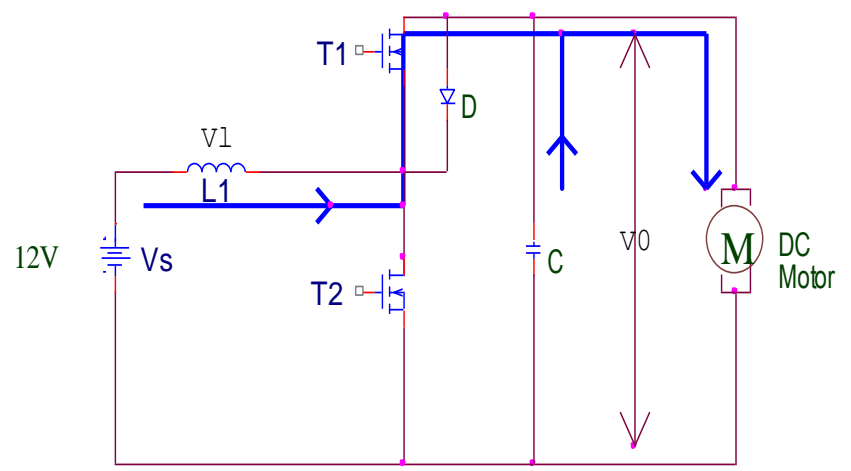

Fig 4.Acceleration 
When duty cycle is increased, the chopper output voltage which is applied to armature terminals increases and this increases the speed of the motor until it matches with the speed corresponding to reference voltage preset by the microcontroller. In other case when load increases speed decreases and the motor draws more current and this decreases the motor terminal voltage. The decrease in armature voltage is sensed and compared with reference to generate positive error signal. In order to minimize the error signal pwm modulator increases the duty cycle D so that speed increases to its previous value and the motor is said to be operating in accelerating mode. During this acceleration mode, energy flow from battery and capacitor. The capacitor supplies the instantaneous energy required to meet the load demand as shown in figure 4

\section{Mode 3: Regenerative Braking Operation}

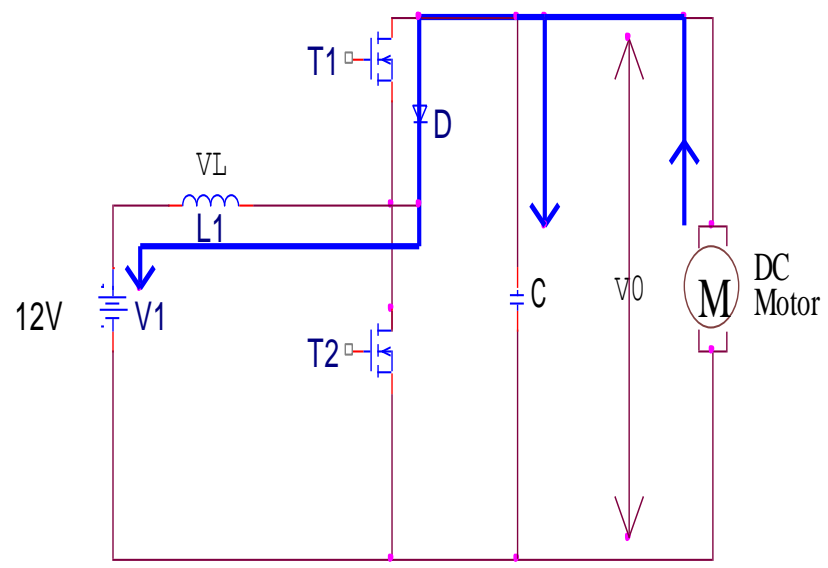

Fig 5. Regenerative Braking operation

When motor is driving high speed and when both switch are turned off supply voltage is disconnected .The motor act as generator and the kinetic energy of motor is converted to electrical energy The regenerated energy flows back into battery and capacitor. The antiparallel diode facilitates the reverse flow of energy into the battery. The diode is forward biased as long as the regenerated emf is greater than battery voltage. The inductor of bidirectional converter ensures the constant current charging of battery and capacitor stores the instantaneous regenerated energy. Thus the regenerated braking energy is recovered in capacitor and battery. Regenerative braking mode is as shown in figure 5.

\section{SIMULATION RESULTS}

Simulation is carried out using MATLAB/SIMULINK for different modes of operation for a simulation time of 10 seconds.

\subsection{Constant Speed Operation}

In this mode the electric vehicle drives at constant speed of 120 radian per second as shown in figure 6(a). since the motor is drawing at constant speed it draws constant current as in figure 6(b) and battery soc decreases linearly as shown in figure $6(\mathrm{c})$.

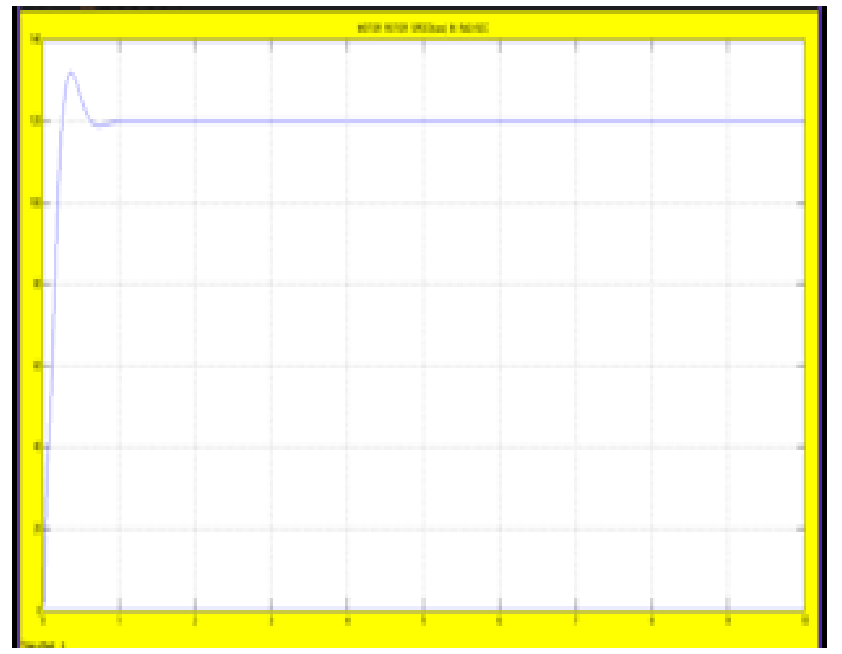

Fig 6 (a). Speed of motor during constant speed operation

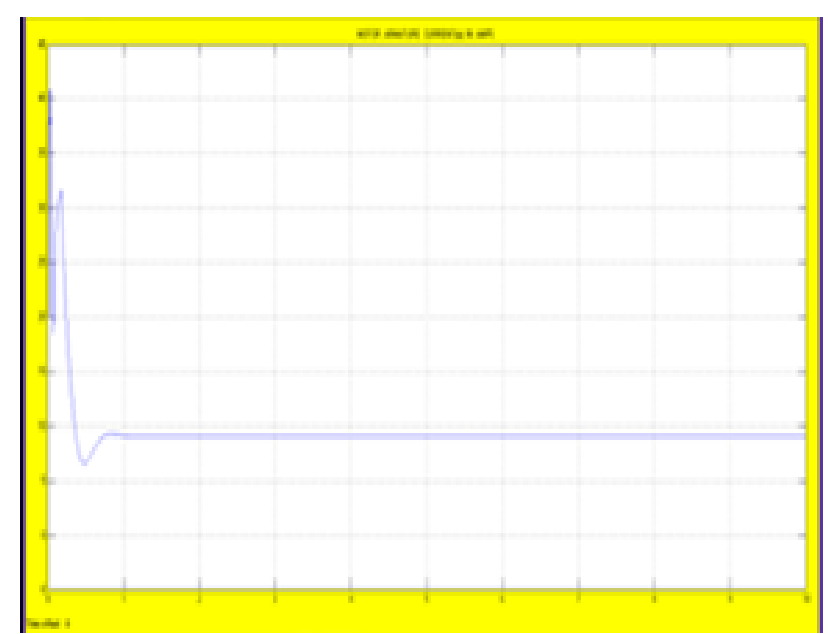

Fig 6(b). Armature current during constant speed operation

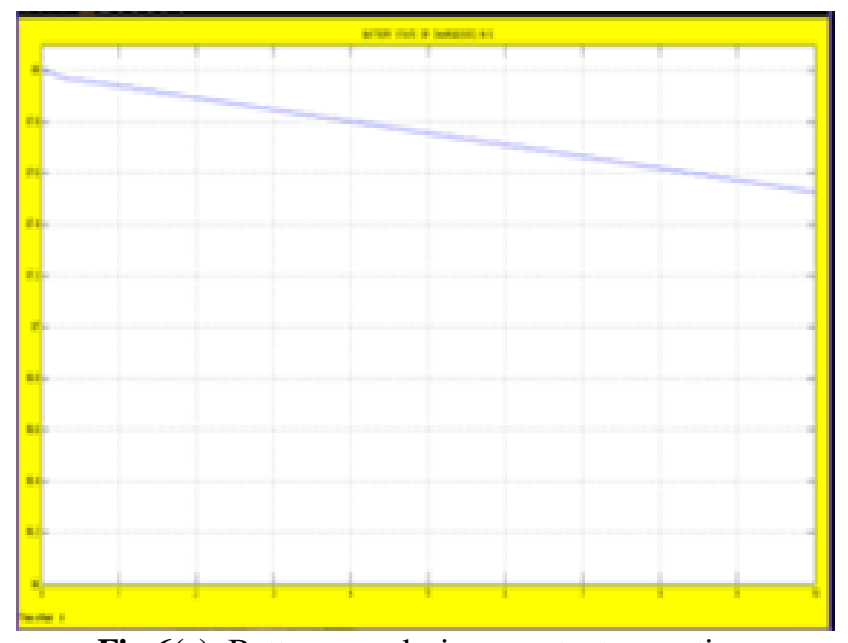

Fig 6(c). Battery soc during constant operation

\subsection{Acceleration Operation}

In this mode speed increases as shown in figure 7(a). and motor draws instantaneous current as shown in figure 7(b)and battery soc starts decreasing rapidly as shown in figure $7(\mathrm{c})$ 


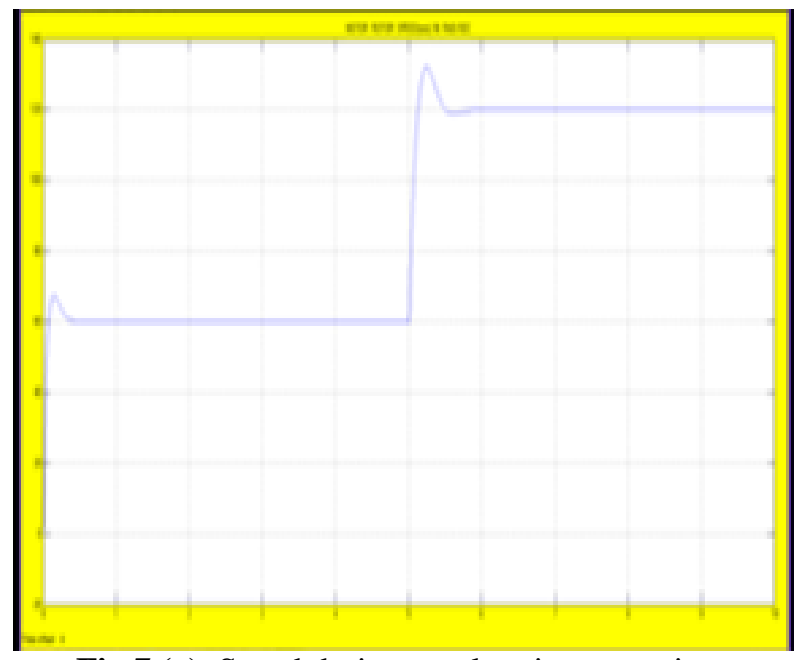

Fig 7 (a). Speed during acceleration operation

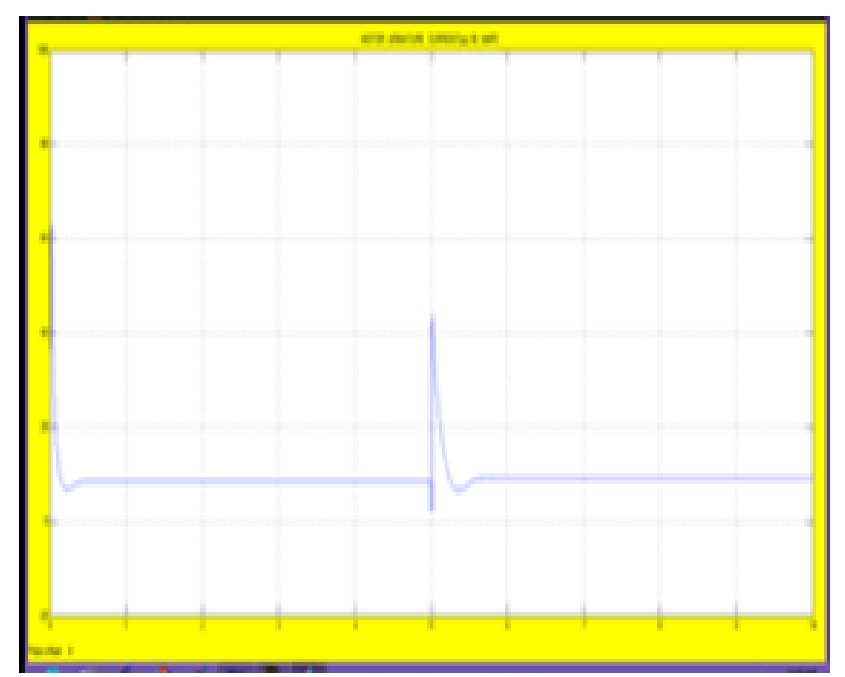

Fig 7(b). Armature current during acceleration operation

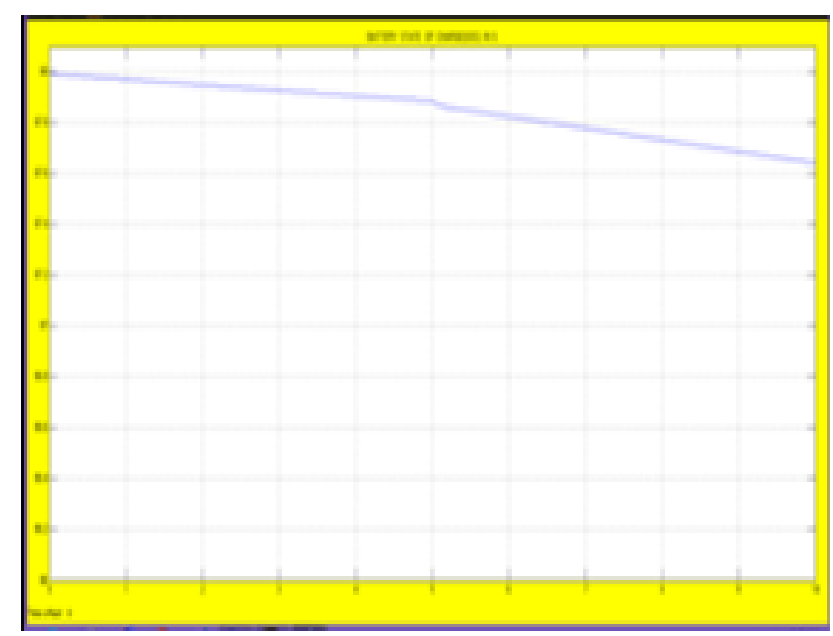

Fig 7(c). Battery soc during acceleration operation

\subsection{Braking Operation}

During braking operation speed of motor is reduced as shown in figure8 (a) and. The negative armature current as in figure8(b) indicates that energy being fed back from motor to the energy storage systems and the battery soc increases as shown in figure8(c)

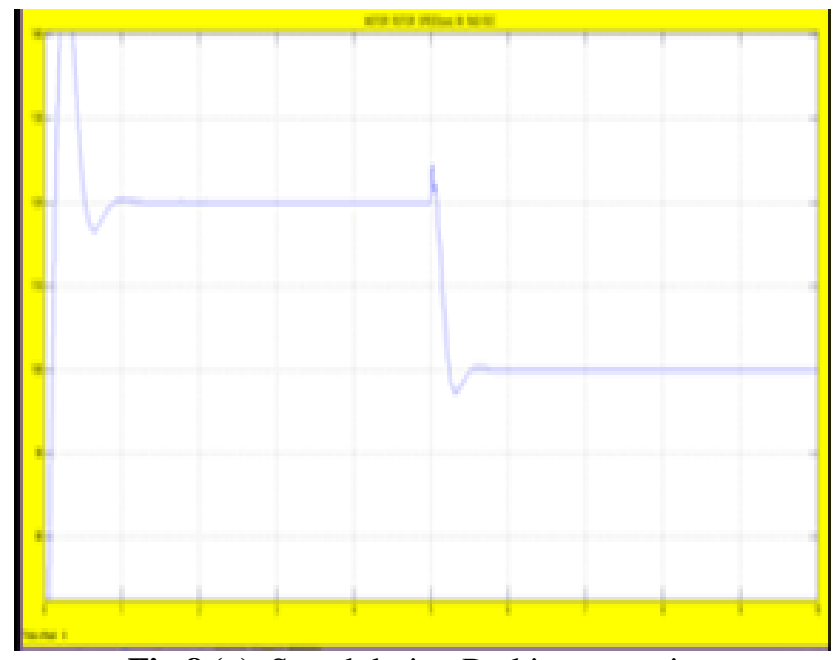

Fig 8 (a). Speed during Braking operation

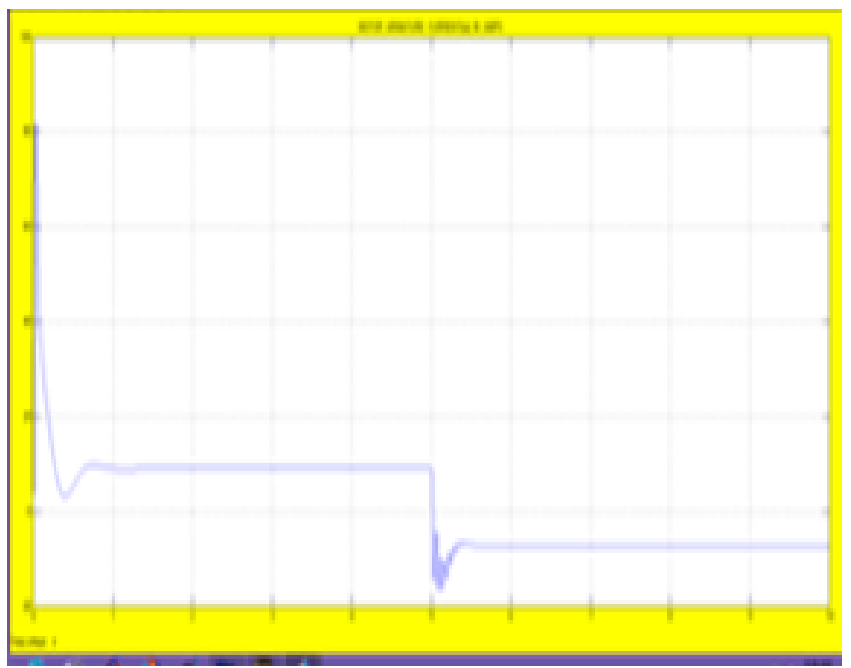

Fig 8(b).Armature current during braking operation.

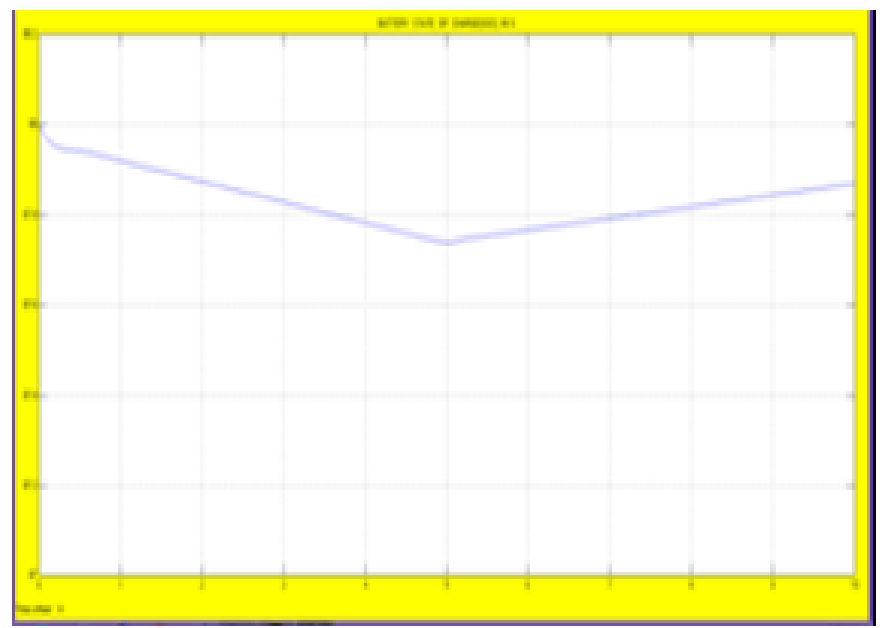

Fig 8(c).Battery soc during braking operation.

\section{EXPERIMENTAL VERIFICATION}

Hardware implementation is shown in figure 9. Switching pulses for the mosfets of bidirectional chopper with $10 \%$ duty cycle and $40 \%$ duty cycle is shown in figure 10 and figure 11 respectively 


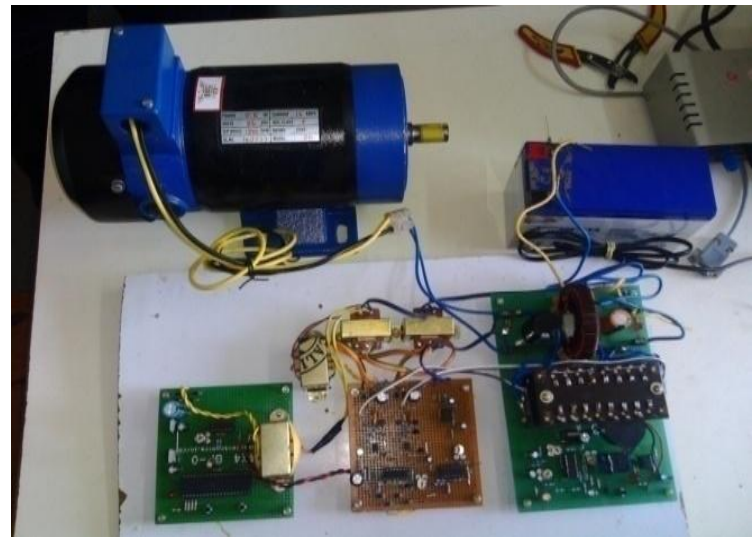

Fig 9. Experimental setup.

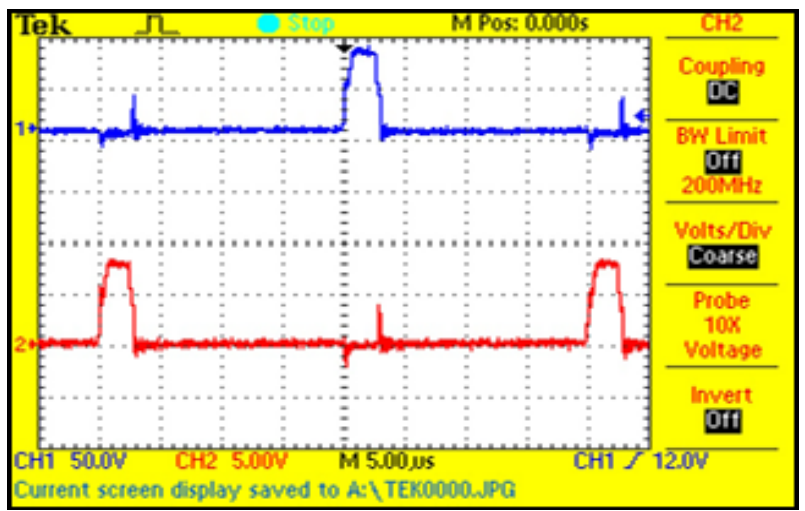

Fig 10.switching pulse with $10 \%$ duty cycle

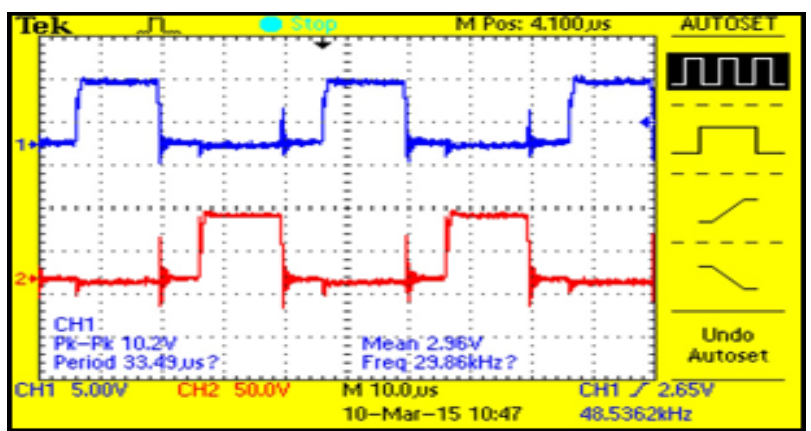

Fig11. Switching pulse with $40 \%$ duty cycle

A graph of experimental results is plotted as shown in figure 12. It includes the plot of armature voltage verses duty cycle and plot of speed verses duty cycle. The plot shows the satisfactory result that increasing duty cycle increases the armature voltage and hence increase in speed
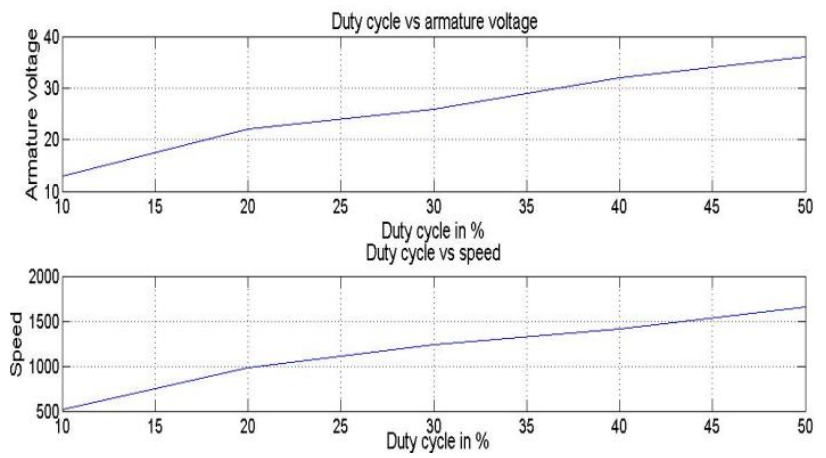

Fig 12. Duty cycle vs. armature voltage and speed of motor

\section{CONCLUSION}

Electric drive using bidirectional chopper is presented. It facilitates the energy recovery during braking operation. Ultra capacitor provides instantaneous energy recovery during braking operation and instantaneous energy supply during acceleration operation. Matlab simulation and experimental results indicates the validity of the system. The above system gain more importance in the near future however the limitation of the system could be the cost due to the cost of ultra capacitor, size of battery, size of the converter. Therefore future work of this system could be focus on selection of ultra capacitor verses size of battery and converters which may reduce the cost of the system . It may also be to focus on working of above system with high voltage heavy traction applications.

\section{REFERENCES}

[1]. Jian Cao, Ali Emadi “ A new battery/ultracapacitor hybrid energy storage system for electric, hybrid plug-in hybrid electric vehicles" IEEE Transactions on Power Electronics ,2007

[2]. Premananda Pany, R.K. Singh, R.K. Tripathi" Bidirectional DC-DC converter fed drive for electric vehicle system" International Journal of Engineering, Science and Technology .Vol. 3, No. 3, 2011, pp.101-110

[3]. Atul Kumar Dewangan, Nibbedita Chakraborty, Sashi Shukla, Vinod Yadu" PWM Based Automatic Closed Loop Speed Controlof DC Motor" International Journal of Engineering Trends and Technology-Volume3Issue2-2012

[4]. Juan W. Dixon, Micah Ortúzar and Eduardo Wiechmann" Regenerative Braking for an Electric Vehicle Using Ultracapacitors and a Buck-Boost Converter," Catholic University of Chile.

[5]. MS. Dipti .k.. Shah, Prof. B. T. Deshmukh, “ DC to DC Drive chopper fed igbt power circuit, " International Journal of Engineering Research and Applications (IJERA), Vol. 2, Issue 2,Mar-Apr 2012, pp.220-222

[6]. Xiaofei Liu, Qianfan Zhang, Chunbo Zhu, "Design of Battery and Ultracapacitor Multiple Energy Storage in Hybrid Electric Vehicle"

[7]. Kavita Burse, Siddharth Shukla,. Vikas Jain "Study of Energy Saving Through Regenerative Braking In DC Drive" ISSN: 2278-7844,2012

[8]. Rohit Gupta, Ruchika Lamba, Subhransu Padhee “ Thyristor Based Speed Control Techniques of DC Motor: A Comparative Analysis" International Journal of Scientific and Research Publications, Volume 2, Issue 6, June 2012 1ISSN 2250-3153

[9]. Ned Mohan,Tore M. Undeland, William Robbin, ” power electronics"wiley india publishing private limited [10]. Dr. P.S. Bhimra "Khanna publishers, new delhi110002 